\title{
Does Catholic education make sense? Exploring the alumnae's experiences
}

Cacho, Rebecca $\square$

De La Salle University, Philippines (Rebecca.cacho@dlsu.edu.ph)

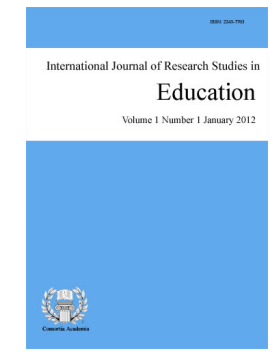

Accepted: 19 May 2021

ISSN: 2243-7703 Online ISSN: 2243-7711

OPEN ACCESS

\section{Abstract}

This article presents the results derived from a tracer study on the impact of Catholic Education on some graduates of St. Scholastica's College, Manila, Philippines. It highlights their perspectives in connection to the values-oriented formation programs culled from the Benedictine Spirituality which they underwent vis-à-vis their degree program in college. True to the 21st century thrust towards holistic education, this brand of Catholic education envisions the graduates to become agents of social transformation while they pursue excellence in their career or chosen profession. The alumnae's perspectives were retrieved through online administered questionnaire distributed through Face book accounts or email correspondences with alumnae who responded to the survey. Generated answers were tabulated and computed to get the mean scores for the variables being studied and the verbatim remarks from their narratives were organized into categories (or by way of thematization) in parallel with the Benedictine values considered in the study. Findings that showed "high mean scores" were indicative of the effectiveness of the values formation programs the School has provided them while those with "low mean scores" reveal the areas to be improved in the educative process which their shared-experiences articulated. The tracer study deviated from the traditional intention of most schools when they conduct tracer study where they only investigate on the employability rate of their graduates because the main focus of this research was to follow up and gauge the significant impact of life skills and core values inculcated in the graduates.

Keywords: Catholic education; values-oriented curriculum; Benedictine hallmarks of education; tracer study; integration of values in education; holistic formation of graduates 


\title{
Does Catholic education make sense? Exploring the alumnae's experiences
}

\section{Background of the study}

St. Scholastica's College, Manila, Philippines takes pride in its thrust of providing Catholic education to its students which is steeped on the Benedictine Hallmarks of Education culled from the Spirituality of St. Benedict of Nursia. All its programs especially the curricular and co-curricular offerings are geared towards the development of socially responsible students who are envisioned to become agents of social transformation towards a just and humane society. In particular, the School of Accountancy, envisions its graduates to be:

\begin{abstract}
competent professional accountants who are persons-for-others and deeply conscious of their social commitment; life-long learners who have the ability to work with others in a consultative process in cross-cultural and cross-border setting; imbued with Benedictine values and dedicated to the continuous pursuit of academic excellence (Student Manual of Information, 2020, p. 23).
\end{abstract}

After years of education, one may ask if the said vision was attained. This study was undertaken to assess how effective was the brand of Catholic education provided for the students particularly on their values formation. Besides finding out the professional status and academic growth of its alumnae, much premium is also emphasized on how the Benedictine values they learned in school are exemplified in their personal and professional lives once they graduate. Were the graduates able to sustain the Benedictine values taught to them? To what extent are these values continually being re-interpreted and re-appropriated in their own varying contexts?

Tracer studies are sometimes referred to as follow-up studies because they trace individuals after an event has taken place in order to determine how this has impinged on their lives since then. The ILO Thesaurus (http://www.ilo.org/thesaurus/default.asp) defines tracer study as an assessment tool where the "impact on target groups is traced back to specific elements of a project or program so that effective and ineffective project components may be identified." Schomburg (2003) believes that such studies provide basis for "analysis of the relationship between higher education and work," (p. 36). Tracer studies in general grant access to quantitative-structural facts about placement and work, competencies or skills, experiences and professional orientation of graduates. This retrospective analysis provides the school with a firm grounding of future innovations while it may also validate how effective or ineffective the program(s) from the perspective of graduates who responded and provided data for the study.

In her book, Introducing Tracer Studies, Cohen (2004) provided guidelines on how tracer studies could be administered more effectively. Her involvement in the Bernard van Leer Foundation's program on tracer studies was used as a basis for the suggested paradigms and methodologies which may facilitate future studies of institutions like St. Scholastica's College, Manila. According to this author, the method of tracing used in their studies "showed us how much can be learned and built upon from such a qualitative exploration," (p. 5). Through tracer studies done, the effects and impact of their early childhood development program brought them a deeper understanding on how to adjust and develop it further so that it will benefit their community better.

Note that while most tracer studies may focus on finding out if their graduates were gainfully employed and properly placed according to their academic preparations/qualifications, this study paid special attention to the core values of the School of Accountancy and the Benedictine values of the College which their graduates were envisioned to have developed while in school with an assumption that these are still being sustained and nurtured even when they have already graduated. In gauging the effectiveness of this aspect of the school's educational program, the school could monitor, plan and even make necessary changes in its curricular, co-curricular offerings, pedagogies, as well as the delivery or implementation of programs. More innovations and remedies

22 Consortia Academia Publishing (A partner of Network of Professional Researchers and Educators) 
may also be devised to respond to the needs of students. Just like other institutions the results of this tracer study hopes to improve education and training programs as well as enhance the learning experiences of future learners of the School of Accountancy in St. Scholastica's College, Manila, Philippines. While it was focused on one-degree course, the study may be replicated by other schools and colleges as it provides initial findings on the impact of Catholic Education with special emphasis on its values-oriented programs and could model further researches on the impact of a specific pedagogical thrust of an educational institution.

\section{Literature review}

Catholic schools often claim that what makes their brand of education unique from other schools is because of their thrust of providing holistic development to their students with premium placed on the values formation programs they offer which may not be available in other secular educational institutions. In a study conducted by Aquino (2015) which focused on the core values of Columban College, the respondents from the different stakeholders showed that there is much room for improvement in their values formation. It was noted that only their religion teachers consciously exerted efforts to instruct students while other subject teachers showed lack of skills in integrating values in their lessons. Likewise, exemplifying the values being taught was also limited, thus the intended effect of the formation program was not satisfactory. It was recommended that values formation which is at the core of their vision must be reinforced by all stakeholders through training, opportunities for service learning, modeling of values especially by the school administrators and the united efforts of all concerned members of the community to pursue this objective of the school. Despite the poor turn-out shown by the findings of the study, one should pay attention to students' remarks on the importance of being educated according to the core values espoused by their school in order to help them become better individuals.

A study conducted by Hazaymeh and Dela Peña (2014) in their school showed that their graduates are highly employable due to academic competencies but it was noted that they lack certain values being considered for promotion and tenure in the companies they were employed in. The data generated revealed that their "top three moderately developed values include commitment, faith, hope, honesty \& diligence,” (p. 66). However, the researchers found it alarming that their graduates did not consider God as the center of their life which was a core value stipulated in their school's vision. They suggested that the "curricula be revisited and improved to meet the necessary skills and competencies expected of their graduates," (p. 63). The formation of values be reviewed and enhanced in order to graduate students who are fully equipped not only with academic knowledge and skills but more importantly, with values that will complete their education and ensure the development of their character.

Jimenez (2009) underlined the importance of values in a community to attain harmony and ensure holistic formation of people. The goals of schools could not be achieved if the members do not share common aspirations and values. But promoting values or inculcating them in students or the members of the community is often challenging. He believes that "the most efficient way to foster values is to reinforce good practices and behaviors that better reflect the desired organizational culture" (p. 16). Without values, there is no clear direction to follow and the efforts of people would end up in mediocrity. Excellence is often achieved when people know what they highly prize or prioritize in life. Putting into practice values or set of behaviors expected of a person is a personal choice. No matter how authoritarian a teacher is if students do not assume the same values, years of training would not ensure assent to such values. In the end, it is important to show good examples rather than speak eloquently about the values which the members of the community should adhere to. The study validated the effective impact of teachers becoming role models of values to students as the best pedagogy in values formation.

Hadi (2015) in a study on the character formation of the youth in Indonesia, concluded that "the most frequently offered solution to overcome or at least reduce the magnitude of the problem of character deviation in society is through education. One's character should generally be maintained in a way, to preserve good characteristics and maintain the unique aspects of each individual," (p. 2). He believes that without the 
Cacho, R.

intervention of education, the vision of a better society may not be achieved. It is said that through education, the values one hopes to develop in young people may be possible. Based on the data gathered in his study, it was found out that "the teaching of values will be more effective if it is conveyed through other subjects considering that teachers of other subjects are knowledgeable about their fields so that they know exactly where these values may be found in their subjects," (p. 19). In other words, the concerted efforts of all those who are engaged in the education of the youth could effectively contribute to the total growth of students.

Jovkovska and Barakoska (2014) investigated through a study if the kind of education which adolescents receive may affect the choice of values and value orientations of these youth. Findings of the study revealed that there was a significant difference in value orientations of young people depending on the kind of education they received. Those who had ethical formation and religious education have formed better life orientations and set of values that guide their way of life. The study showed that it is necessary for educational institutions to provide for their students all the conditions that will facilitate inculcating of moral values towards integral development since "the path and perspectives of development of a society depend on the values formed among adolescents today and their level of preparedness for the new changes in social relations," (p. 1). Indeed, religious and values education play a vital role in shaping the mind and heart of a person; ensuring a better society through their efforts and initiatives ignited by the kind of education made available for them.

\subsection{Summary}

The review of literature and studies available reveals the need to periodically revisit, revise, enrich or even change the school's approaches and pedagogies being adopted for their values or character formation programs to achieve the impact they envision for their students. One factor that has recognizable reference to all the schools' findings was the indispensability of role modelling by the adults like faculty, parents and school administrators. Reinforcement of values may be achieved if all the members of the school community are one in their efforts and initiatives with consistency and integrity. While academic excellence and competent or job-ready students are produced, many graduates are lacking in values that are necessary to live well in society. It was noted that companies prefer to employ graduates who are not only skilled in their work but are imbued with sound ethics and human values that ensure good relations in the workplace.

\section{Methodology}

The study made use of the descriptive method of research which is concerned with description and interpretation of data. Current conditions, opinions and structures affecting the study are noted for systematic analysis and examination (Best \& Kahn, 1998). A combination of qualitative and quantitative data collection and analysis techniques was utilized. Note that qualitative approaches in the form of narratives enabled the researcher to have an in-depth insight about the key variables or core values under investigation. On the other hand, the quantitative approach, provided data that enabled statistical inferences in determining the effectiveness of the Catholic Education offered by St. Scholastica's College, Manila.

Respondents of this tracer study were 56 graduates who responded from the on-line survey forms sent to them or posted in social media accounts such as Facebook, and email account. Graduates from 1999-2014 were asked to answer the forms but only a few responded to the survey. In spite of the low turn-out of returned questionnaires from the respondents, it is noteworthy to consider what data were generated and how these may initially and tentatively give the school some basis to gauge the effectiveness of the values formation program in connection to the brand of Catholic education espoused by the school. Certain insights and lessons may be derived from the data gathered which could be of use to the said school and perhaps to other educational institutions which may share similar thrust or vision for their graduates.

The survey questionnaire was developed by the proponent of this study and content validated by two Benedictine sisters who have been involved extensively in Benedictine Formation whether in the convent among 
their novices or with the schools where they were accorded supervisory and important leadership functions. The Likert scale was used for the survey type of questionnaire administered to the graduates. Pilot testing was also employed among randomly selected graduates to validate its reliability. With the results from the pilot testing and the statistical treatment validated by the school's statistician, the survey questionnaire was approved for use in the study and was administered through online communications with the alumnae or respondents of this study. In order to analyze and interpret the results of the survey done, the researcher made use of frequencies and mean scores to present the quantitative aspect of the study. The rate provided by the alumnae were tabulated and computed to arrive at both the mean and mode scores respectively. The frequencies and mean scores were the basis for gauging the impact of the program on the graduates. On the other hand, the narrative part of the survey or verbatim remarks of the responses, were synthesized and thematized; arranging them according to categories which correspond to specified Benedictine values so as to see if there are possible parallelisms with the values intended by the school for its graduates with the values these alumnae continue to exemplify in their personal and professional life. Such process also allows for discovery of "continuity or discontinuity" of the values in the graduates, while being able to pinpoint which values are more favored by the graduates among the Benedictine values taught to them.

\section{Key findings and discussions}

Besides the Benedictine values being inculcated in the students of the College, the School of Accountancy's brand of education reiterates the values of life-long learning and striving to be persons for others. As life-long learners, the graduates are enjoined to continually engage in education whether formally or informally in order to grow in their craft. It is the vision of the school to see their graduates as accomplished women in their field of expertise where thirst for knowledge and skills is sustained even after they graduate and are already working. In the same light, graduates are inspired to be persons who are always ready to reach out to the needy especially the poor and the marginalized in the community. Providing financial assistance, employment, educational scholarships, special training and the like are only some of the efforts started by the school which are hoped to be continued by its graduates even when they are no longer connected to the school's outreach activities or similar initiatives.

In general, the respondents' answers indicated a continuous practice of the Benedictine and Core Values of the school as they rated the extent of their practice of values as either extensively done or moderately applied. This implies that the values continue to permeate their personal and professional lives even after graduation. Note that in the study conducted by Jovkovska and Barakoska, (2014) it was concluded that those who had ethical and religious kind of education in college often develop better life orientations and set of values when they graduate and pursue their career. Hadi (2015) in a study on the character formation of the youth in Indonesia found out that without the intervention of education, the vision of a better society may not be expected. It is said that through education, the values one hopes to develop in young people may be possible.

Being educated in a school that gives premium to inculcating Benedictine values, the respondents of this study rated the continuous practice of the said values with an overall mean of 3.64 which is interpreted as moderately done. The table that follows indicate the area mean per value. For life-long learning, the mean score is 3.91 which show that this is moderately being observed by the graduates. Similarly, persons for others garnered a rate of 3.43 , or moderately practiced and for being socially responsible professionals, 3.58 as its area mean which is also moderately applied in their lives.

At first glance, the ratings given may be lower than what may be considered as the ideal but when examined closely, the rates are still at par with the expectations of the school. This means that though not perfectly assumed in their professional lives, the graduates did not forget the values taught to them. While some may have been exemplified more than the others, one will clearly see that all the values are still given due importance by the alumnae. 
Cacho, R.

Table 1

Ratings on the school of accountancy's core values

\begin{tabular}{|c|c|c|}
\hline Core values & Mean & Interpretation \\
\hline Life-long learning & & \\
\hline $\begin{array}{l}\text { How would you rate the contribution of the program of your study/course to your personal } \\
\text { knowledge, skills and attitudes? }\end{array}$ & 4.03 & extensive \\
\hline $\begin{array}{l}\text { To what extent does continuous study through seminars, conferences, research or higher } \\
\text { studies help you grow in your career? }\end{array}$ & 3.96 & moderate \\
\hline Have you contributed to initiatives that showcase innovation and creativity? & 3.76 & less extensive \\
\hline Persons for others & 3.91 & moderate \\
\hline $\begin{array}{l}\text { How would you rate your involvement in advocacies that focus on poverty alleviation in } \\
\text { our country? }\end{array}$ & 2.87 & less extensive \\
\hline How have you been active in the promotion of gender equality/respect for woman's rights? & 3.57 & moderate \\
\hline Have you exerted efforts to promote peace and pursue it in yourself and in others? & 3.85 & moderate \\
\hline Socially responsible accounting professionals & 3.43 & moderate \\
\hline To what extent do you practice Ora et Labora in your present context? & 4.10 & extensive \\
\hline How would you rate your participation in promoting truth and honesty in your workplace? & 3.69 & moderate \\
\hline To what extent did the school able to model simplicity of lifestyle? & 3.67 & moderate \\
\hline Are you involved in any activity that concretizes care for the environment? & 2.87 & less extensive \\
\hline e & 3.58 & moderate \\
\hline Overall mean & 3.64 & moderate \\
\hline
\end{tabular}

In other words, the rate for all the core values which the respondents gave may not be exceptional, but one could clearly see that the said values were not forgotten or taken for granted by the graduates. It may also be due to the nature of their work who are mostly assuming managerial positions in the companies they are employed which resulted to a less extensive rating in item number one under persons for others. This does not mean, however, that they do not exert efforts to reach out whenever possible in fact when opportunities to help present themselves, they readily extend support to the needy as expressed in their verbatim remarks. This low mean score of 2.87 could also be considered as a priority value for the school to reinforce further. In other words, there is much room for improvement in this area so as to be consistent with the school's advocacy of taking an active part in poverty alleviation initiatives or projects in society. In a similar study conducted by Hazaymeh and Dela Pena (2014), their graduates are highly employable due to academic competencies but it was noted that they lack certain values being considered for promotion and tenure. Thus, they recommended intensifying the values formation program of their school so that their graduates are not only formed in academic competencies but will also display values that engender good character.

Moreover, when it comes to the living out of "ora et labora," graduates rated this as extensively observed. This is a very good indication that the most basic expression of Benedictine spirituality had the strongest impact in their lives. This lifestyle is most relevant and meaningful to them. Prayer and hard work were easiest for them to assimilate which is indicated by their admission of its continued influence in the way they live. All the respondents mentioned this phrase in their narrative answers or verbatim remarks. It is indicative of its strong influence in their lives since their college days in St. Scholastica's College. Such that after many years of leaving the portal of their alma mater, they still carry on with this principle. The Catholic education with a Benedictine character strives to ensure that the design and life of the campus promotes a spirit of transcendence and mindfulness, encouraging all to cultivate a life of prayer appropriate to their own faith. The intent of all of this is to cultivate by analogy a fundamental openness to the work of intellectual as well as personal transformation.

Another concern which may have garnered a less extensive mean score is the concrete effort to exemplify stewardship or care for environment which was rated 2.87 , or could be interpreted as less extensive. One probable reason is the option to choose an advocacy which would be more in keeping with or in line with their profession. Others may have focused on those areas that advocate for immediate responses to pressing social issues or concerns in their efforts to do something concrete for the good of society. Some claimed that in their field of work the values of integrity and honesty were given more weight, gaining moderate score of 3.69, so as 
to maintain and preserve what the school has taught them about not compromising the truth despite many temptations in their job whether they are employed in private or public companies and institutions. As part of the Christ-centered life being promoted among Scholasticans, there is always a call to pursue a rigorous and disciplined search for truth. Even when circumstances become difficult, they are enjoined to stay honest and keep their integrity intact. In summary, the core values of the school as stipulated in their vision, mission, goals have taken root in the lives of their graduates. There is an evident impact of these values in their being even after graduating from the school. Although some may not have the extensive impact intended, one could not deny its continued influence in the lives of the graduates. Not one of their core values were missed out even when they may not have been extensively pursued after graduation. There is an evident effort to remain faithful to the ideals set by the school.

For the second part of the survey made regarding the Ten Hallmarks of Benedictine Education, the table that follows would show that all the hallmarks received high scores. Each of the area mean rendered a score which is above 4 points interpreted as extensive in the scale. This is a very satisfactory result when gauged in the quantitative aspect of the study.

\section{Table 2}

Ratings for the hallmarks of Benedictine education

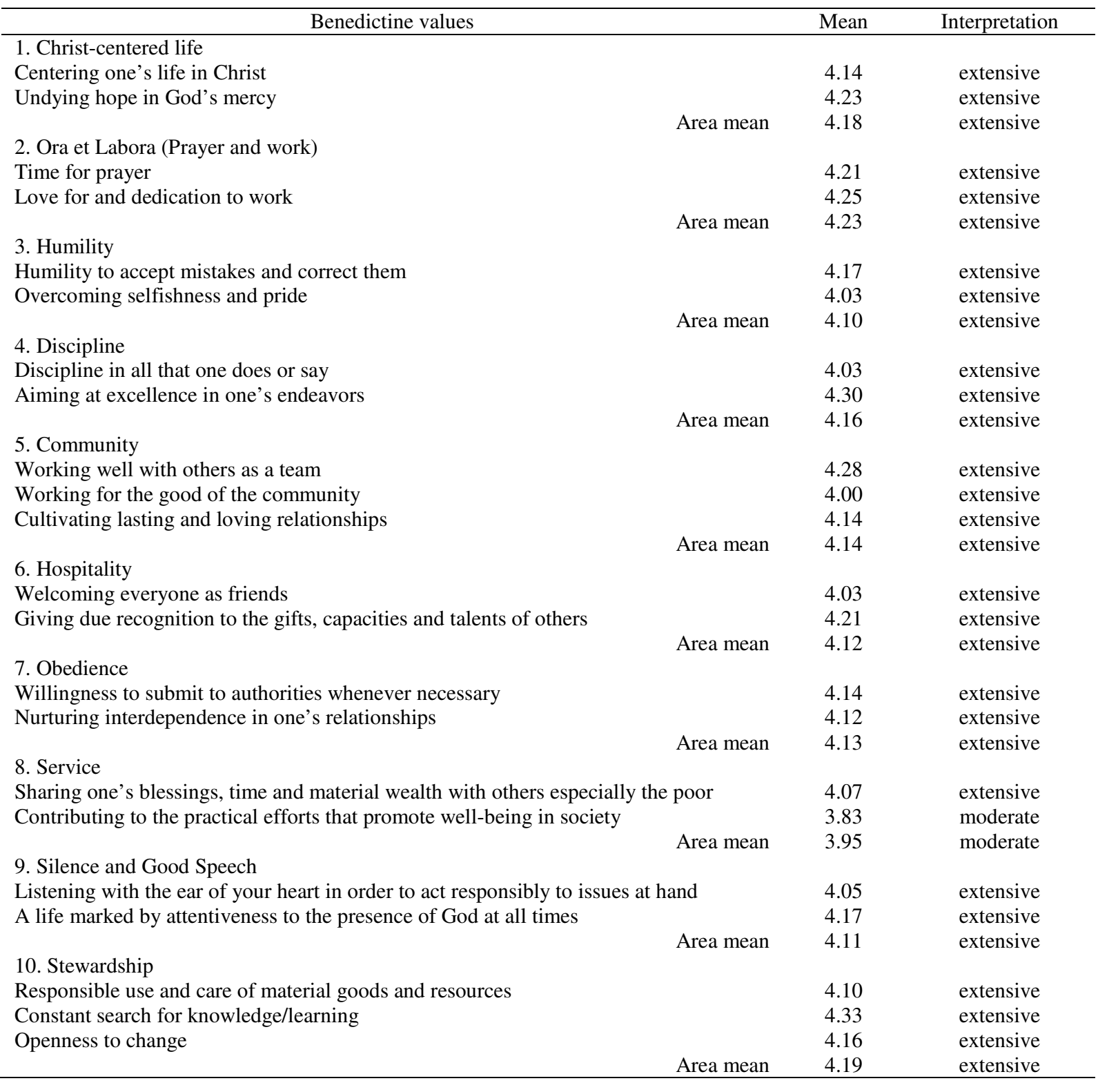


Looking at the area mean of all the Ten Hallmarks of Benedictine Education it is noticeable that ora et labora has the highest score with an area mean of 4.23. As mentioned in the previous part of this study, it is clear that these values have been the most influential in the lives of the graduates. Second is the value of stewardship, with 4.19 points for its area mean. The constant search for knowledge is given much weight in this hallmark. Graduates give more time to professional growth so as to be more competent in their work or the position they hold in the company they are part of. They would want to be considered truly reliable and worth respecting in the field.

Christ-centeredness has garnered 4.18 points for its area mean which is not very far from the previous value mentioned. As a Catholic school, this is prioritized among the ten. It is clear that the graduates have also realized the importance of the value in their lives to have scored as extensively practiced in the survey done. All the rest of the ten were also given due consideration by the respondents since they all scored extensively applied. This indicates that these values are very satisfactorily being sustained by the graduates. Among the ten however, service to others has an area mean of 3.95 or moderately exemplified due to less extensive efforts they have done or engaged in after graduation. The practical ways of contributing to the good of society may have been understood within the scope of extension services or charitable efforts in poor communities which was the practice when they were still in school. There is a need for the school to re-define the concept of service to others beyond the traditional "dole-outs" or immersion to poor communities. The Benedictine value of service transcends the usual "charity efforts" because whatever profession a person practices may be considered as genuinely serving others. Sincere commitment to contribute to the well-being of others must be understood as service to one's society. Instruction on this while in school may be intensified so as not to limit the practice of this value in charity works.

In terms of the other item on the same value which is sharing with the needy whatever they have, one will see that they are practicing this extensively. Between these two items under the same variable, sharing may be more easily done. Generous sharing of resources with the poor and the needy is easily attributed to the school's extensive contribution to relief operations undertaken when calamities occur in the country. Since their grade school years, students of St. Scholastica's College have been educated to share what they have with the poor as an expression of support and solidarity. The culture of giving has already been familiar to those schooled in this institution even at a young age.

In summary, the ten hallmarks have scored higher than the core values of the school of accountancy. This indicates that the Hallmarks of Benedictine Education are being exemplified in the lives of graduates. They are not only familiar with the values but have also continued to live them out beyond the scope of their college education. Re-appropriation and re-interpretation in their present contexts are being done no matter how tentative or simple they may be.

In order to see more clearly which of the values were more frequently mentioned by the respondents through their narratives or verbatim remarks, the table that follows present a synthesis using the frequency scale and ranking them with the same consideration or standard.

Table 3

Benedictine advocacies being continued by the respondents

\begin{tabular}{lcc}
\hline \multicolumn{1}{c}{ What are the advocacies that you are still committed to? } & Frequency & rank \\
\hline Poverty alleviation & 21 & 1 \\
Gender equality/women empowerment & 10 & 4 \\
Life-long learning & 19 & 2 \\
Persons for others & 18 & 3 \\
\hline
\end{tabular}

Upon comparison with the score given in the first two parts of the survey on poverty alleviation efforts, there seems to be a discrepancy. While in the survey it has garnered a mean score of 2.87 which is less extensively done, in their verbatim remarks, it has ranked first among the core values in terms of frequency. This

28 Consortia Academia Publishing (A partner of Network of Professional Researchers and Educators) 
means that most of them give premium to this advocacy when asked if they still continue the school's thrust towards social transformation. The least frequently mentioned was the issue on gender equality. This may be attributed to the context by which they may be found at this point in their career. Most of them are already assuming higher positions in their corporations as well as being accorded respect as women leaders whether in the corporate world or in their social relationships. Being promoted in their positions and enjoying equal chance with others may also be the cause of this seeming inactivity in gender empowerment. Since they have been reaping the rewards of being empowered in their own field, there are limited occasions by which they need to stand for this advocacy such as fighting for their rights or earning respect from people. There are however, narratives which some graduates related that ascertain their mindfulness and efforts to promote gender equality especially in the corporate world where ignorance to rights and dignity of being a woman still prevails.

In the next table, the proponent weeded out the frequency by which the ten hallmarks of Benedictine education have been mentioned by the respondents. The results show that most of the values are still known to the respondents.

\section{Table 4}

Benedictine values mentioned in the narrative part of questionnaire

\begin{tabular}{|c|c|c|}
\hline Benedictine values & Frequency & rank \\
\hline Christ-centeredness & 25 & 3 \\
\hline Ora et labora & 43 & 1 \\
\hline Community & 28 & 2 \\
\hline Stewardship & 13 & 7 \\
\hline Discipline & 15 & 6 \\
\hline Service & 20 & 5 \\
\hline Humility & 18 & 8 \\
\hline Hospitality & 21 & 4 \\
\hline Obedience & 6 & 10 \\
\hline Silence and good speech & 10 & 9 \\
\hline
\end{tabular}

It is noticeable that the survey results corroborate the verbatim remarks of the alumnae. While ora et labora received an area mean of 4.28 points which is interpreted as extensively done and the highest rank for the quantitative data, the frequency by which it was mentioned in the narratives of graduates has also shown the graduates' preference for these values to be integrated in their lives. The quantitative data is consistent with the qualitative information gathered through their verbatim remarks. Obedience was less mentioned among the ten. While this is very important among the members of the missionary Benedictine sisters of Tutzing (RB 71: I-2), this may not have been emphasized in the school as it trained students to be articulate and assertive of what they believe is right. According to the Rule of Benedict, obedience is putting into practice what is learned by listening to the other "with the ear of the heart" (RB, Prol. I). Indeed, students are also trained to listen and be mindful of authorities. There are even opportunities to do lectio divina to train them in this skill but college schedule may have put pressure and restrictions on them such that devoting time to do this Benedictine style of listening was very limited. This may also clarify such less familiarity with the practice implied in the verbatim remarks of the respondents.

In the last part of the data presentation and interpretation, some of the striking remarks or comments stipulated by our respondents are presented in order to synthesize the experiences, perspectives and lessons the graduates attributed to their school and the Catholic brand of education they received.

\section{Table 5}

Some notable verbatim remarks of respondents

\section{Quotations}

I use my Benedictine values to overcome challenges... and to stand out among the rest

Thru the Benedictine values instilled in me I can say that I am dedicated, well-rounded and well-grounded individual

Given the nature of our work, wherein we handle sensitive and confidential information, I try to uphold integrity at all times 
Table 5 ...continued

Quotations

I believe I have lived out the Benedictine values since I graduated and I am grateful for the school for instilling these values in me

Since college I have incorporated Ora et Labora in my way of life

I always find myself valuing every responsibility given to me and I find fulfilment in balancing prayer and work

The Benedictine values taught me to adapt to circumstances without compromising my values

My Benedictine education taught me to strive for excellence, humility, social responsibility and integrity

I can say that my Benedictine education formed me to be socially responsible and to be committed to my work as it can contribute to social change

I practice honesty in all dealings both personal and professional to promote integrity

I learned in SSC that when I go to work I shouldn't chase for success but pursue excellence and let the former chase me

St. Scholastica's education has equipped me to face the daily challenges of life

It has taught me to be brave, to be vocal, to be compassionate to others

My Scholastican education taught me to think selflessly and help the less fortunate

As a Scholastican, I am committed to promote gender equality/respect for woman's rights

One of the values that greatly impacted me is stewardship

I am truly grateful for being a finished project of the accountancy program in St. Scholastica's College, Manila

A professor in St. Scho has told us always "sign your work with excellence." This is one of the important lessons I

learned in college and this has guided me in what I do.

I chose to study in St. Scholastica's College not because it is one of the prestigious schools but because it does not only

help us excel academically but molded us into agents of change

The Benedictine values I got from studying were put into challenge as I work in government institution

I learned to raise the bar by constantly challenging my team to sharply question the status quo in order to spark

innovation and change

Learning to live simply and work passionately

In my profession, I deal with different kinds of people and I treat them with respect regardless of our differences St.

Scholastica's College taught me to share and give back to community the blessings that I received from God

I strive to be honest, responsible and hardworking even if it means putting behind any personal gain

I believe I am a holistic person because of the Benedictine values imbibed in me

I am an advocate of empowering people, helping them achieve their dreams

The balance of prayer and work instilled by my Scholastican education has become the cornerstone of my life after I left college

The value of silence has given me peace in spite of pressures in the work place

I am very proud at how Benedictine values have shaped my whole being since college. I had also been in other Catholic schools but it is in this school that I learned discipline

In everything I do, I put Christ at the center. This is something precious that I learned from St. Scho

I describe the Scholastican community as friendly and loving environment, with God as the center of our life

Through a closer look at the narratives written by the respondents, one will be awed by the respect and pride implied in the statements they articulated whenever they look back at the kind of Catholic education, they have received from their Alma Mater. No one expressed any regret or reservations in lavishing the school with expressions of gratitude and high regard for the institution. Most of the descriptions articulated were actually lengthy which indicates that the graduates took time out to relate their experiences and provide greater clarity to their answers in the survey part of the questionnaire. Many volunteered some information even when such were not asked but this is a good indication of how open they were to providing the school some feedbacks that may ascertain the positive impact of the Benedictine education they received. There was a heightened awareness of how their college education significantly changed their life or improved their personality.

The Hallmarks of Benedictine education as well as the core values in the School of Accountancy instilled in them were not only fondly remembered but were re-appropriated in the workplace. Most of them admitted passing on this Benedictine brand of education to their children not only in terms of parenting but also by sending their children, relatives or friends to St. Scholastica's College, Manila to receive the same education they have had. One may conclude that generally the goals of the school have been successfully achieved. This may be the result of hard work and shared aspirations and values of the administrators and faculty. Indeed, promoting values or inculcating them in students or members of the community is often challenging. According to Jimenez (2009), "the most efficient way to foster values is to reinforce good practices and behaviors that better reflect the desired organizational culture," (p. 16). 


\section{Summary and conclusion}

The study was conducted to determine the effectiveness of the values formation program of the School of Accountancy. Results of the study indicated a very positive impact of the Catholic education provided by the school to its students. With the Catholic brand of education being advocated by St. Scholastica's College, Manila, particularly through the School of Accountancy, one may conclude that the vision, mission and goals have been met. Through this study, an initial assessment of the values formation program was completed, thereby providing validation of its effectiveness. Although there are some areas to be improved, re-defined, emphasized and re-structured, the data will not discount the fact that the school has fulfilled its dream for its graduates particularly in imbuing them with Benedictine values that contributed to the growth and development of its students. There was not only relevance or meaningfulness linked to Benedictine education but also an affirmation that the direction being pursued suggests a sound pedagogy being employed. This is also in keeping with the patron's aspiration which is clearly stipulated in the Rule of St. Benedict:

And so we are going to establish a school for the service of the Lord.

In founding it we hope to introduce nothing harsh or burdensome.

But if a certain strictness results from the dictates of equity for the

amendment of vices or the preservation of charity,

do not be at once dismayed and fly from the way of salvation,

whose entrance cannot but be narrow (Matt. 7:14).

For as we advance in the religious life and in faith,

our hearts expand and we run the way of God's commandments

with unspeakable sweetness of love. (RB, Prologue)

All the efforts exerted and initiatives undertaken did not go to waste. Graduates highlighted the significant contribution the school has done in their development not just professionally but also personally. The area mean scores in all the values, whether on the core values or the Benedictine values of the institution were not rated simply based on their familiarity with terms but were clearly founded on continued living out of these values as reiterated in their verbatim remarks or narratives. There are no articulations or statements that reveal incompetency or lack of integrity in the delivery of total quality education. In fact, one will not miss out on the expressions of gratitude and high respect they have accorded not just to the faculty but to the whole Benedictine community for the education they have received.

Comparison between the mean scores of the core values of the school of accountancy and the ten hallmarks of Benedictine education indicated that majority of the respondents rated the Benedictine values higher than the core values of the school. As such, the administrators, faculty and staff that make up the specific department may be enjoined to review, improve and intensify their concerted efforts to be more effective values facilitators among their students. Besides individual instructions, consistency in words and deeds, role modeling and opportunities to practice those values must be provided, it is necessary that the whole community be involved in the formation of their students. All must share a common goal and aspire for the same values so as to permeate the learning environment with a distinct culture they want their students to assimilate and witness to specially when they graduate.

While it is true that the respondents were grateful to the kind of education they received in the school, much is still to be enhanced or improved. For one, the area mean for poverty alleviation efforts is less extensive with 2.87 points as its score compared to other core values, thus, the school may consider how this could be intensified so that graduates may have the platform on which they could continue this in their own field. Likewise, more attention must be given to the realization of environmental care which garnered 2.87 points as its area mean score, which is interpreted as less extensively done. While the concept is understood and the value recognized, graduates are lacking in their efforts to make this value more palpable. Other opportunities or 
Cacho, R.

projects may be crafted and offered by the school to make this value a reality and not just an ideal.

The initial findings generated from the tracer study commissioned by the school administrators in terms of the impact of Catholic education is unique in the sense that it was not only concerned with finding out the job placement of their graduates but was more focused on the values they have imbibed from the school. Unlike most tracer studies which primarily assess the effectiveness of academic instruction so as to ensure that their graduates will be employable, the study may serve as impetus to conducting tracer study in connection to the character or values education their graduates have assimilated in their brand of education. It must be noted that the 21st century skills do not only target academic excellence or skills directly related to jobs but also consider total human development with certain human values in place.

In this study, the brand of Catholic education provided by St. Scholastica's College, Manila generated more positive results compared to previous studies done as mentioned above. Responses from the alumnae may have the potential to inspire schools to consider a shift from their current practices or pedagogies towards a more effective character or values formation program for their students. The findings highlight the experiences of the graduates who have benefited from the formation program of their alma mater thereby affirming and validating the effective implementation of curricular and co-curricular activities in their school. While it may provide inspiration for its faculty, staff and administrators, it also prods them to do something about the weak areas of the Catholic Education they offer to their students.

Schools are enjoined to conduct similar tracer study to use as basis for revisions of current developmental programs or introduction of educational engagements that do not only provide opportunities for academic excellence and work-related competencies but also oriented to developing life skills, high emotional intelligence, and sound human values which could serve as their moral compass in a world beset by moral decay and degradation of values. With values-imbued young people, education has not only given them the chance to earn for a living but also equipped them with the capacity to be catalysts of social transformation which is a most urgent task for humans to embark on.

\section{References}

Aquino, C. (2015). The five core values of Columban College as exemplified by its stakeholders as a way of achieving authentic Christian leadership [Thesis]. Manila: De La Salle University.

Banzuela-de Ocampo, M., Bagano, A., \& Tan, A. (2012). Culture of entrepreneurship versus employment. Academia.edu Web. https://www.academia.edu/36131668/Culture_of_Entrepreneurship_versus_Employment

Best, J., \& Kahn J. (1998). Research in education (8th ed). Massachusetts: Allyn and Bacon.

Blue Cloud Abbey. (n.d.). The rule of Benedict. OSB.org Web http://www.osb.org/rb/text/rbejms1.html\#pro

Cohen, R. (2004). Introducing tracer studies. Netherlands: Bernard van Leer Foundation.

Comunicaciones Web. (n.d.). Retrieved from http://significanceofvalues.com/formayion/index.html

ela Cruz L., \& Ferrer E. (1999). Effectiveness of partnership and commitment to volunteerism. Quezon City: Voluntary Service Overseas Philippines.

Fasset tracer study: The value of work readiness programmes. (2013). South Africa: EE Research Focus.

Hadi, R. (2015). The integration of character values in the teaching of economics: A case of selected high schools in Banjarmas. International Education Studies, 8(7). https://doi.org/10.5539/ies.v8n7p11

Hazaymeh, E., \& Dela Pena, M. (2014). A tracer study of La Salle University College of Engineering Graduates. Lasallian Research Forum, 18(1), 52-68.

ILO Thesaurus. (n.d.). International Labour Organization Web. Retrieved from http://www.ilo.org/thesaurus/default.asp

Institutional Testing and Evaluation Office. (2012). The effectiveness of the Hybrid Courses at De La Salle University [Thesis]. Manila: De La Salle University.

Jimenez, J. (2009). The significance of values in an organization. Venezuela: Cograf. 
Does Catholic education make sense? Exploring the alumnae's experiences

Jovkovska A., \& Barakoska A. (2014). The role of education in the formation of values and value orientations among adolescents. International Journal of Cognitive Research in Science, Engineering and Education, 2(2). Retrieved from https://www.ijcrsee.com/index.php/ijcrsee/article/view/137/143

Schomburg, H. (2003). Handbook for graduate tracer studies. Centre for Research on Higher Education and Work, Germany: University of Kassel Web. Retrieved from http://www.qtafi.de/handbook_v2.pdf Student Manual of Information for College. (2020). Manila: St. Scholastica's College, Manila.

The Benedictine Hallmarks of Education. (n.d.). Retrieved from https://www.gonzaga.edu/academics

The Rule of Saint Benedict. (1931). Retrieved from https://www.solesmes.com/sites/default/files/upload/pdf/rule_of_st_benedict.pdf

Vong C. (2015). Graduates of 2012: A tracer study. Cambodia: Royal University of Phnom Penh. 
Cacho, R.

34 Consortia Academia Publishing (A partner of Network of Professional Researchers and Educators) 